\title{
Presentación
}

\section{Ciencia, tecnología E INNOVACión EN COLOMBIA: ¿PARA QUÉ?}

Gonzalo Ordóñez-Matamoros ${ }^{*}$

En Colombia, la discusión política sobre el papel de la ciencia, la tecnología y la innovación (CTeI) en el desarrollo es prácticamente inexistente $\mathrm{y}$, ante todo, retórica. Algunos asocian la CTeI a su valor económico relacionado con el crecimiento, la productividad y la competitividad. Otros, la asocian al bienestar, a la solución de problemas sociales, a la salud y al ocio. Hay quienes, tomando la perspectiva de la prevención, llaman la atención sobre sus implicaciones y riesgos para la inequidad, para la exclusión social, territorial o productiva. También hay quienes resaltan las amenazas que le plantea la CTeI al medio ambiente, al empleo, a la seguridad e incluso a la misma existencia humana.

En otras palabras, en el debate político colombiano estas son ideas que, dependiendo del contexto y el interlocutor en cuestión, se abordan bien sea como algo romántico, en reconocimiento de su valor y potencial, o bien con una perspectiva fundamentalista o apocalíptica, en reconocimiento de sus riesgos. De cualquier manera, se refieren a la CTeI como algo "ajeno", externo, propio de otros, venido de otras personas, instituciones o países. En el imaginario colectivo de los estamentos gubernamentales o estatales dicha imagen es particularmente evidente.

En cualquier caso, del optimismo o del escepticismo en torno a la CTeI, propia o ajena, no trasciende prácticamente nada identificable en el quehacer de los gobiernos en Colombia, a pesar de su rápida aceleración ad portas del siglo XXI. En el caso de los optimistas, el papel de la CTeI aparece esporádica y pomposamente en anuncios públicos de campaña política. Los oferentes privados de "soluciones" la promocionan como vendiendo ilusiones y esperanzas. Los escépticos, por su parte, se refieren a las implicaciones éticas (y nada más) cuando aparece un escándalo mediático asociado al engaño o al plagio. En el sector privado, el escepticismo no es bienvenido a pesar de su gran potencial en pro de un buen producto o servicio innovador.

\footnotetext{
* Doctor en Políticas Públicas. Director del Centro de Investigaciones y Proyectos Especiales (cipe), Facultad de Finanzas, Gobierno y Relaciones Internacionales, Universidad Externado de Colombia, Bogotá (Colombia). [gonzalo.ordonez@uexternado.edu.co]; [https://orcid.org/0000-0002-8297-6554].

Para citar esta presentación:

Ordóńez-Matamoros, G. (2020). Ciencia, tecnología e innovación en Colombia: ¿ppara qué? operA, 27, 5-9 DOI: https://doi.org/10.18601/16578651.n27.01
} 
En lo que tiene que ver con la postura gubernamental en torno a la CTeI en Colombia, solo recientemente se ha venido incluyendo en los últimos cuatro planes de desarrollo, en algunos documentos del Consejo Nacional de Política Económica y Social (Conpes) (entre ellos algunos "fallidos" que nunca vieron la luz pública) y en los planes de desarrollo de algunos departamentos.

Más recientemente, la CTeI ha sido objeto de preocupación en el contexto del Sistema General de Regalías (más por sus malos usos y la corrupción, que por sus méritos y contribución al desarrollo local), y aún más recientemente, en algunas leyes procurando corregir "fallas del mercado" para garantizar la libre competencia o para ver cómo debería funcionar Colciencias como nuevo ministerio.

Los optimistas, públicos o privados, no han logrado permear con sus discursos y sus promesas el aparato estatal ni a la sociedad en su conjunto. En Colombia, la CTeI se asume (porque se vive) importante pero poco se entiende y menos se hace algo al respecto. No es sino constatar lo poco que se invierte en la producción de conocimiento en general, y en CTeI en particular (Colombia solo gasta en $\mathrm{I}+\mathrm{D}$ menos del $0,3 \%$ del producto interno bruto [PIB], mientras que el promedio de los países de la Organización para la Cooperación y el Desarrollo Económicos [ocDE] es del 2\% del PIB) o en su aprovechamiento, y ni hablar de su debido monitoreo y control.

De manera que, contrario a la tendencia mundial propia del inicio del siglo xxI, en Colombia la CTeI o las políticas públicas para su producción, difusión, uso o control son verdaderos "anatemas".
La pandemia de la Covid-19, desatada a principios de ańo, es tal vez la más clara oportunidad para que la sociedad colombiana y su Gobierno miren hacia la CTeI como actividad importante. Bien sea porque ven en ella la única esperanza de vida para muchos, o, al contrario, porque pudo haber sido la causa del virus mismo, o porque la perciben como la mejor herramienta para sobrellevar el confinamiento de la mejor forma posible. A pesar de ello, a casi seis meses de conocido el riesgo, no hay claridad sobre qué puede hacer el Gobierno al respecto a fin de aprovechar la CTeI como recurso para enfrentar la crisis de salud pública, o para mantener andando la economía hoy en parálisis, ni cuál debería ser el rol del nuevo ministerio de CTeI en este contexto. La CTeI en Colombia es característica de la metáfora del elefante en la entrada de la casa, donde todos lo notan y a todos llama la atención, pero nadie hace nada al respecto.

Este número especial de la Revista OPERA viene en un momento muy propicio para contribuir, desde la academia, a llamar la atención y dar luces sobre la importancia y las formas de llenar el vacío aludido entre discurso y acción en torno al papel de la CTeI en el desarrollo económico y social colombiano. En este caso en particular, se trata de debates necesarios y aún inexistentes (incluso en la academia) que se espera permeen la opinión pública, tanto la ilustrada como la poco informada, y el quehacer de los gobiernos a través de sus políticas públicas. Se enfoca en uno de los contextos más decisivos en la historia y futuro del país: la inclusión social y la paz, en aprovechamiento de la expresión revelada de partes tradicionalmente en conflicto, y donde claramente la 
CTeI tiene (y podría tener aun más) un papel crucial tanto para aprovechar las oportunidades que se ofrecen como para contener las amenazas que implican.

Se trata, entonces, de una invitación a revisar las agendas públicas en un contexto en el que la CTeI (el elefante en la entrada de la casa) es una realidad que no se puede seguir ignorando, para que dichas agendas gubernamentales, del orden nacional, departamental y local, sean revisadas y actualizadas. Con esto, se espera que la discusión que aquí se da, la cual tiene múltiples aristas, contribuya a una Colombia más desarrollada e inclusiva, sostenible, segura y en paz. Esta tarea no se puede seguir aplazando.

Y es que, en general, la relación CTeI-paz no ha sido suficientemente estudiada en la literatura universal. En el plano político se ha venido gestando a nivel global, principalmente en cabeza organismos multilaterales como la Unión Europea y las Naciones Unidas, un debate sobre el carácter responsivo que deberían adoptar las políticas de CTeI en el mundo. Es el caso del creciente interés en vincular el desarrollo económico y social con la CTeI a través de enfoques alternativos como el de los Grand Challenges, los Objetivos del Milenio, los Objetivos de Desarrollo Sostenible, la Innovación Inclusiva, la Innovación para la Base de la Pirámide, la Responsible Research and Innovation, la innovación de base (grassroots innovation), la innovación frugal, entre otros, muy en boga actualmente en Europa pero cuyo debate se originó principalmente en India, Tailandia, Brasil y Argentina.

Sin embargo, ninguno de tales debates hace alusión explícita a la paz como objetivo alcanzable con CTeI. Por razones históricas, Colombia bien podría liderar un ambicioso programa de investigación en dicho sentido, pues la paz es un anhelo esquivo de más de medio siglo que debería motivar su estudio desde todos los ángulos posibles, incluida naturalmente la comprensión del diálogo de saberes entre el conocimiento ancestral y la llamada cuarta revolución industrial, entre otros temas relevantes.

En el marco de un artículo recientemente publicado sobre el tema, algunos autores identificamos cinco retos importantes para lograr la alineación entre la CTeI, las políticas públicas para su promoción y la paz en Colombia. Entre ellos se identificó: a) la necesidad de reconsiderar nociones básicas como conocimiento, ciencia, tecnología e innovación, y su papel en el desarrollo como objetos de política pública de CTeI; b) el papel del Estado, del mercado y de la política de CTeI en un país tan diverso en potencial y oportunidades, y con tantas necesidades desatendidas con apego al conocimiento; c) la necesidad de focalizar los esfuerzos de política pública de CTeI para abarcar nuevos temas/problemas ignorados; d) la responsabilidad moral de la política de CTeI a la luz de las tres formas de exclusión identificadas como relevantes en el marco de los acuerdos de paz con la exguerrilla de las FARC: la exclusión social (segmentos de la sociedad son típicamente excluidos por y de la CTeI y las políticas de su promoción), la exclusión sectorial (tiende a haber prelación en unos sectores/actividad económica o social sobre otros) y la exclusión territorial (hay regiones de la geografía colombiana que son marginadas de toda oportunidad posible); y e) implicaciones 
en torno al esquema de gobernanza, necesarias para que la CTeI contribuya de manera efectiva a una paz estable y duradera en Colombia (Ordóñez-Matamoros et al., 2018). De dicha discusión queda claro que, si bien los retos son grandes, las dinámicas en torno a una efectiva transformación ya empezaron a dar tímidos, aunque importantes, frutos.

$Y$ es que, en general, existen antiguas preguntas sin resolver y aparecen nuevas en torno a la CTeI y su papel en el desarrollo (Cozzens et al., 2008; Bortagaray y Ordóñez-Matamoros, 2012). En un trabajo anterior se trató, junto con el profesor Stefan Kuhlmann de la Universidad de Twente y una treintena de autores de distintos lugares del mundo, de evaluar la racionalidad y la relevancia de las políticas de CTeI implementadas en economías emergentes como Colombia (Kuhlmann y Ordóńez-Matamoros, 2017). Hoy nos preguntamos específicamente ¿cómo luciría un aparato político y estatal volcado en Colombia a la nueva realidad donde prácticamente todo está permeado por la CTeI? ¿Cuáles deberían ser las prioridades, las políticas, los programas, los instrumentos y los proyectos llamados a aportar a la Colombia anhelada en el siglo XXI? ¿Cuáles deberían ser los arreglos institucionales en las distintas carteras de gobierno en el marco de esta realidad? ¿Cuáles deberían ser los mecanismos de regulación y control en dicho contexto? ¿Cuál el esquema de gobernanza con actores tradicionalmente ignorados como la universidad, la ciencia ciudadana, los spinoffs, las comunidades ancestrales, etc.? ¿Cómo responder a las demandas desatendidas de la población de manera creativa, innovadora, sostenible y responsable, basados en el conocimiento y la CTel? Estas son preguntas fundamentales que es necesario, no solo formular, sino que requieren esfuerzos materiales para dar respuestas por la vía de programas gubernamentales implementados en Colombia.

La Red de Gobernanza del Conocimiento, la Ciencia, la Tecnología y la Innovación (Red GCTI), compuesta por más de 80 miembros provenientes de distintas disciplinas, entornos institucionales, regiones y países (de la cual soy su presidente y fundador en 2016, y de la que hacen parte los editores de este número especial de OPERA, así como algunos de los autores), es un colectivo interesado en aportar a dicho tipo de debates, tanto académicos como políticos en el contexto colombiano. En este sentido, la Facultad de Finanzas, Gobierno y Relaciones Internacionales de Universidad Externado de Colombia, desde su Centro de Investigaciones y Proyectos Especiales - CIPE, y en particular en el marco de la línea de investigación en Desarrollo Sostenible y Territorial, se ha venido interesando de manera decidida en apoyar iniciativas como la que hoy nos convoca.

Espero que el lector encuentre en este número de opera suficiente ilustración, respuestas, inspiración o nuevas preguntas e interrogantes provocadores para aportar así a una mejor comprensión de los retos que se le plantean a Colombia en el siglo XxI.

Director del Centro de Investigaciones y Proyectos Especiales - CIPE

Facultad de Finanzas, Gobierno y Relaciones Internacionales

Universidad Externado de Colombia 


\section{REFERENCIAS}

Bortagaray, I. y Ordóńez-Matamoros, G. (2012). Introduction to the special issue of the review of policy research: Innovation, innovation policy, and social inclusion in developing countries. Review of Policy Research, 29(6), 669-671.10.1111/j.15411338.2012.00587.x

Cozzens, S. E., Gatchair, S., Kim, K-S., Ordóńez, G. y Supnithadnaporn, A. (2008). Knowledge and development. En E. D. Hackett, O. Amsterdamska, M. Lynch y Wajcman, The Handbook of Science and Technology Studies (3 ed., pp. 787-811). Cambridge, MA: MIT Press.
Kuhlmann, S. y Ordóñez-Matamoros, G. (eds.). (2017). Research handbook on innovation governance for emerging economies. Towards better models. Cheltenham: Edward Elgar Publishing.

Ordóńez-Matamoros, G., Centeno, J. P., Arond, E., Jaime, A. y Arias, K. (2018). La paz y los retos de la política de ciencia, tecnología e innovación en Colombia. En C. Soto (ed.), Seguimiento y análisis de politicas públicas en Colombia (Anuario 2017, pp. 137-168). Recuperado de https://publicaciones.uexternado.edu.co/pageflip/acceso-abierto/ pdf/anuario-seguimiento-y-analisis-2017.pdf 